\title{
The Role of Mast Cells Mediators in Angioedema Without Wheals
}

\author{
Anna Sala-Cunill, M.D, PhD ${ }^{1,2, *}$ \\ M. Guilarte, M.D, Ph. $D^{1,2}$
}

\author{
Address \\ ${ }^{1}$ Allergy Section. Department of Internal Medicine, Hospital Universitari Vall \\ d'Hebron, Passseig Vall d'Hebron 119-129, Barcelona, PC, 08035, Spain \\ ${ }^{*}, 2$ Allergy Research Unit, Allergy Department, Institut de Recerca Vall d'Hebron, \\ Universitat Autonoma de Barcelona, Barcelona, Spain \\ Email: asala@vhebron.net
}

Published online: 7 0ctober 2015

(C) Springer International Publishing AG 2015

This article is part of the Topical Collection on Urticaria and Atopic Dermatitis

Keywords Angioedema $\cdot$ Bradykinin $\cdot$ Histamine $\cdot$ Mast cell $\cdot$ Mediators $\cdot$ Wheals $\cdot$ Classification

\section{Opinion statement}

Angioedema is defined as localized and transient edema of the deep skin layers or the upper respiratory or gastrointestinal mucosa. Although the most common sites of involvement are the tongue, lips, face, and throat, angioedema may also occur in the extremities, genitalia, and viscera, and it can be life-threatening when affecting the upper airway. Angioedema is due to a temporary increase of the vascular permeability caused by vasoactive mediators. However, the mechanisms and the mediators involved in angioedema without wheals vary depending on the type of angioedema. The purpose of this review is to give new insights on angioedema without wheals. To facilitate the understanding of the different types of angioedema, a modified classification of angioedema without wheals from the Hereditary Angioedema International Working Group consensus is proposed. It also summarizes the pathophysiology of the main types of $A E$ and describes the current knowledge regarding the role of the mast cell mediators involved. Finally, given that the treatment of angioedema has changed greatly in the last years, this review also describes the specific treatment options of angioedema without wheals. Gaining knowledge into these pathophysiologic mechanisms of angioedema and into the gaps in the diagnosis will allow to improve the management of these patients, avoiding fatal outcomes.

\section{Key points:}

- Angioedema is a localized, self-limiting, no pitting swelling that can be life-threatening and needs adequate treatment to avoid fatal outcomes.

- The mechanisms and the mediators involved in angioedema without wheals may vary depending on the type of angioedema; therefore, it is important to understand the physiopathology of each type of angioedema to improve the differential diagnoses. 
- There is a need to develop standardized diagnostic tests to differentiate types of angioedema in order to improve management.

\section{Introduction}

Angioedema (AE) is defined as localized and transient edema of the deep skin layers or the upper respiratory or gastrointestinal mucosa. This condition involves the reticular (deep) dermis and subcutaneous and submucosal tissues. Angioedema is due to a temporary increase of the vascular permeability caused by vasoactive mediators. It frequently occurs as part of urticaria, but when angioedema occurs without wheals, it can sometimes manifest with symptoms of pain and tenderness, whereas itching may not be present [1]. Although the most common sites of involvement are the tongue, lips, face, and throat, angioedema may also occur in the extremities, genitalia, and viscera, and it could also be life-threatening when affecting the airway, requiring immediate treatment $[2 \bullet \bullet]$.

This review is focused in angioedema without wheals (AE-WoW) and highlights the pathophysiology of the most important types of angioedema without wheals and the special role of mast cell in these types. Recently, published classifications of AE-WoW are discussed, and a new proposal is suggested. Finally, it gives an overview on the novel therapies for different types of angioedema.

\section{The classification of angioedema without wheals}

Although angioedema is frequently associated with urticaria, it can also occur alone in $10-15 \%$ of the cases $[3,4 \bullet]$. Like urticaria, angioedema results from increased vascular permeability caused by the release of vasoactive mediators. The difference between both conditions lies in the dermis layer where leakage and transudation of plasma occur; urticaria affects the superficial skin layers (papillary dermis), whereas angioedema involves the deeper reticularis dermis, subcutaneous tissue, and the submucosa.

The pattern of swelling is an important diagnostic consideration as well as the association with urticaria. Classically, angioedema without wheals had been classified as bradykinin (BK) or histamine-mediated. Nevertheless, the implication of these vasoactive substances has only been demonstrated in a few patients. An increase of plasma BK has been observed locally during angioedema attacks in hereditary angioedema with $\mathrm{C} 1$ inhibitor deficiency (HAE-C1INH), acquired angioedema with $\mathrm{C} 1$ inhibitor deficiency (AAE-C1INH) and in angioedema due to angiotensin converting enzyme inhibitors (ACEi) [5, 6]. The term histamine-mediated angioedema was established on the basis of the therapeutic response to antihistamines. In 2013, the Hereditary Angioedema International Working (HAWK) group proposed a new classification of angioedema distinguishing hereditary from nonhereditary forms $[2 \bullet \bullet]$. The term BK-mediated was avoided because of the lack of evidence of the implication of BK (BK) in most types of angioedema. Moreover, other vasoactive substances such as substance $\mathrm{P}$, cystenil leukotrienes, or prostaglandins are also implicated in the generation of angioedema. On the other hand, mast cell heparin can activate contact system and the release of BK $[7 \bullet \bullet, 8]$. 
Recently, a new classification based on endotypes has been proposed [9]. In this classification, the different types of angioedema are divided into three groups: those due to an excess of BK, those due to mast cell and basophil degranulation, and a third group (idiopathic). This classification includes other types of angioedema such as NSAID induced or exacerbated angioedema, allergic angioedema, or drug-induced angioedema. However, BK involvement in hereditary angioedema with normal C1 inhibitor (HAE-nC1INH) has not been demonstrated, although it is assumed because of the clinical similarity to angioedema due to C1INH deficiency and the response to drugs targeting BK [10].

We propose a modification (Fig. 1) of the HAWK classification that includes allergic angioedema and NSAID-induced angioedema. In this classification, the currently known pathogenic mechanisms are considered. Although the mechanism of idiopathic angioedema that does not response to antihistamines is currently unknown, a BK-related mechanism seems to be involved in its pathogenesis, and experimental evidence is still limited.

Clinically, BK-related angioedema (hereditary and acquired C1INH deficiency and ACEi-angioedema) and HAE with normal C1INH are slow in both onset and progression and usually last more than $24 \mathrm{~h}$. In contrast, mast cell or basophil-related angioedema is quickly established and lasts $<24 \mathrm{~h}$.

Prevention with antihistamines and speed of onset are nowadays the only clues to diagnose an idiopathic angioedema due to mast cell/basophil activation (histaminergic idiopathic angioedema or idiopathic angioedema that responds

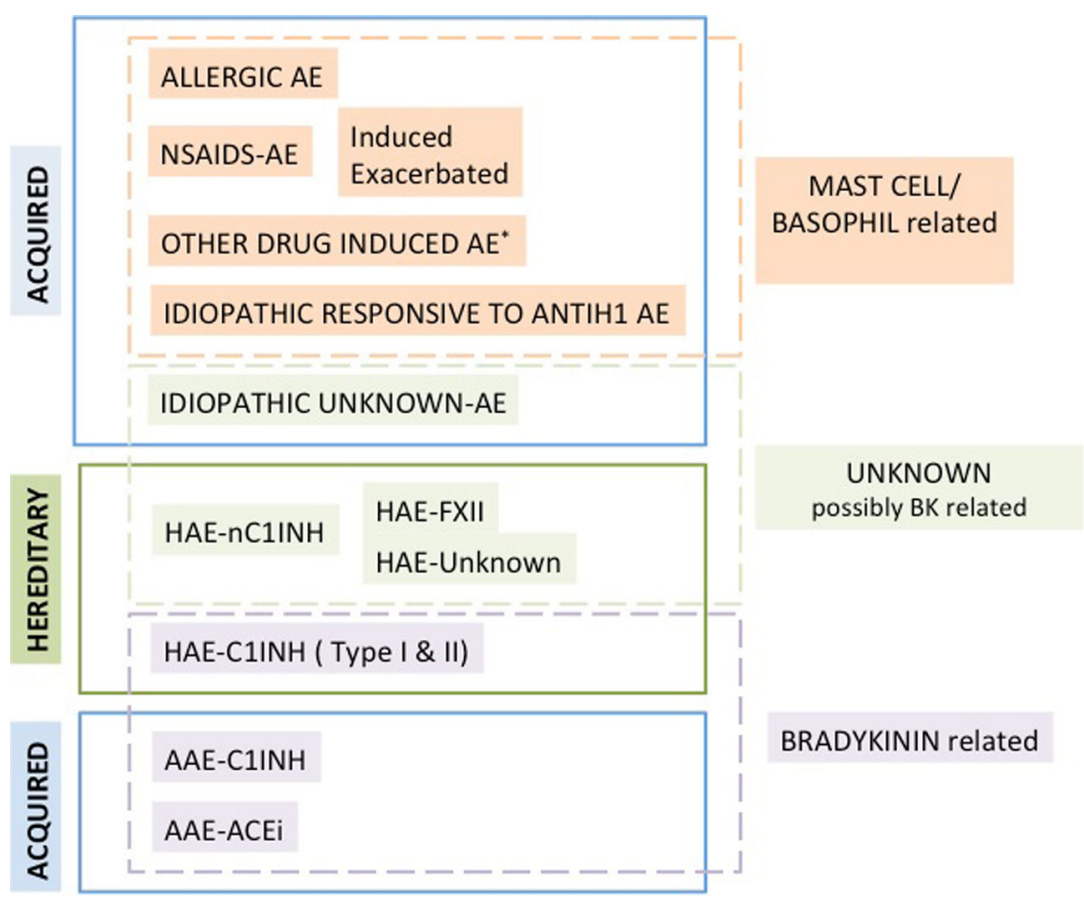

Fig. 1. Classification of angioedema without wheals. 
to antihistamines) because of the lack of an effective biomarker to differentiate it from unknown or nonhistaminergic angioedema.

\section{Mechanisms of angioedema without wheals}

Mast cell-mediated angioedema is pathophysiologically similar to urticaria, although it takes place in deeper levels of the dermis and involved mediators are probably different. With the exception of angioedema due to C1INH deficiency, the pathophysiology of angioedema without wheals is not completely clear. The central effector cell is the dermal or mucosal mast cell which upon activation releases vasoactive mediators such as histamine, prostaglandins, or leukotrienes contributing to the early and late responses [11] with extravasation of fluid into the superficial tissues in urticaria and in the deeper layers of the skin in angioedema. Factors determining the association of AE to urticaria or not are largely unknown.

\section{Mast cell and basophil-related angioedema}

The major immunological pathway related with mast cell activation is IgEmediated type I hypersensitivity. However, in most patients, angioedema is developed without an interaction between IgE bound to mast cells and allergens. In the case of urticaria, the binding of IgG auto-antibodies to IgE and/or to the high affinity receptor for IgE on mast cells has been shown to be the mechanism of activation of mast cell in some patients with chronic spontaneous urticaria (CSU) [12]. This autoimmune or auto-reactive urticaria represents up to $50 \%$ of patients with chronic urticaria. Mast cell activation can also result from type III hypersensitivity through the binding of circulating immune complexes to mast cells/expressing Fc receptors for IgG and IgM [12]. Activation of mast cells can also occur through T cells, membrane receptors involved in innate immunity (anaphylotoxins, Toll-like receptors), or by direct toxicity of drugs or haptens.

NSAIDs can induce angioedema through IgE and non-IgE-mediated hypersensitivity reactions. The latter is linked to the NSAIDs inhibition of cycloxygenaxe-1 (COX-1) leading to an overproduction of cysteinyl-leukotrienes, by increasing the metabolism of arachidonic acid through COX-2 [13]. All NSAIDs inhibiting COX-1 can induce symptoms, and cross-reactions are independent of their chemical structure. Cysteinyl-leukotrienes are vasoactive substances able to increase vascular permeability.

C1-INH prevents uncontrolled activation of factor XII and directly inhibits kallikrein, the enzyme inducing the excision of BK from high-molecular-weight kininogen [14]. Therefore, in HAE-C1INH and AAE-C1INH, the most potent inhibitor of the contact system, decreased activity of C1-INH, results in increased quantities of $\mathrm{BK}$, a vasoactive peptide that is thought to be the primary mediator of swelling in HAE. Accumulation of BK results in increased vascular permeability, vasodilation, and contraction of nonvascular smooth muscle, resulting in the clinical symptoms of HAE [15]. 
Although the mechanism of ACEi-induced AE (ACEi-AAE) is not fully understood [16], it has been associated with the disability of BK, des-Arg ${ }^{9}$-BK, and SP degradation related with ACE inhibition [17]. In one study, high levels of BK were reported in ACEi-AAE patients [18].

\section{Possible bradykinin-related angioedema}

The pathogenic mechanism by which angioedema is produced in HAE$\mathrm{nC1INH}$ is uncertain. The presence of factor XII mutations suggested an increase in contact system activation and a pathogenic role of BK. Nevertheless, the implication of BK in this type of angioedema has not been proven. In most cases, HAE-nC1INH angioedema attacks occur under hyper-estrogenic situations such as pregnancy or use of oral contraceptives. Estrogens can raise BK levels, either increasing its production or altering its degradation. C1INH activity is normally decreased in pregnant women. In addition, increased levels of factor XII have been observed in women taking estrogenic contraceptive pills with high levels of estrogens [19, 20]. Estrogens also increase B2-R gene expression and function [21]. On the other hand, estrogens suppress ACE expression, increasing BK and des-Arg9-BK concentrations [22]. This potential mechanism involved in this type of angioedema has been described recently by Kaplan et al. [23].

However, in the last years, a possible activation of BK-forming cascade in a factor-XII independent way has also been described. This could also have implications in the pathogenesis of hereditary angioedema type I and II [24].

The exact mechanism of idiopathic angioedema that does not respond to antihistamines remains currently unidentified.

\section{Mast cell mediators involved in angioedema}

Mast cells mediators traditionally have been divided in three groups: (1) preformed mediators stored in the cytoplasmic granules released by degranulation (i.e., histamine, tryptase, chymase, carboxypeptidase A and proteoglycans), (2) newly generated proinflammatory lipid mediators (i.e., prostaglandins, leukotrienes, and platelet activating factor (PAF)), and (3) newly synthesized growth factors, cytokines, and chemokines.

The exact effects of each of these mediators are not fully known, although the main actions have been reported. However, the interpretation of these available data is also hampered by the fact that key steps occur locally at the site of initial contact and mediators from this component will not be detectable systemically. Furthermore, the potency of each mediator varies enormously, some of them being 1000 times more potent than others regarding vascular effects, and many pathways are redundant and overlapping, hindering the understanding of the exact role of each mediator. Therefore, antagonizing any single mediator alone is unlikely to render a significant therapeutic effect [25]. Table 1 summarizes the main mediators of mast cells possibly involved in angioedema and their effects. 


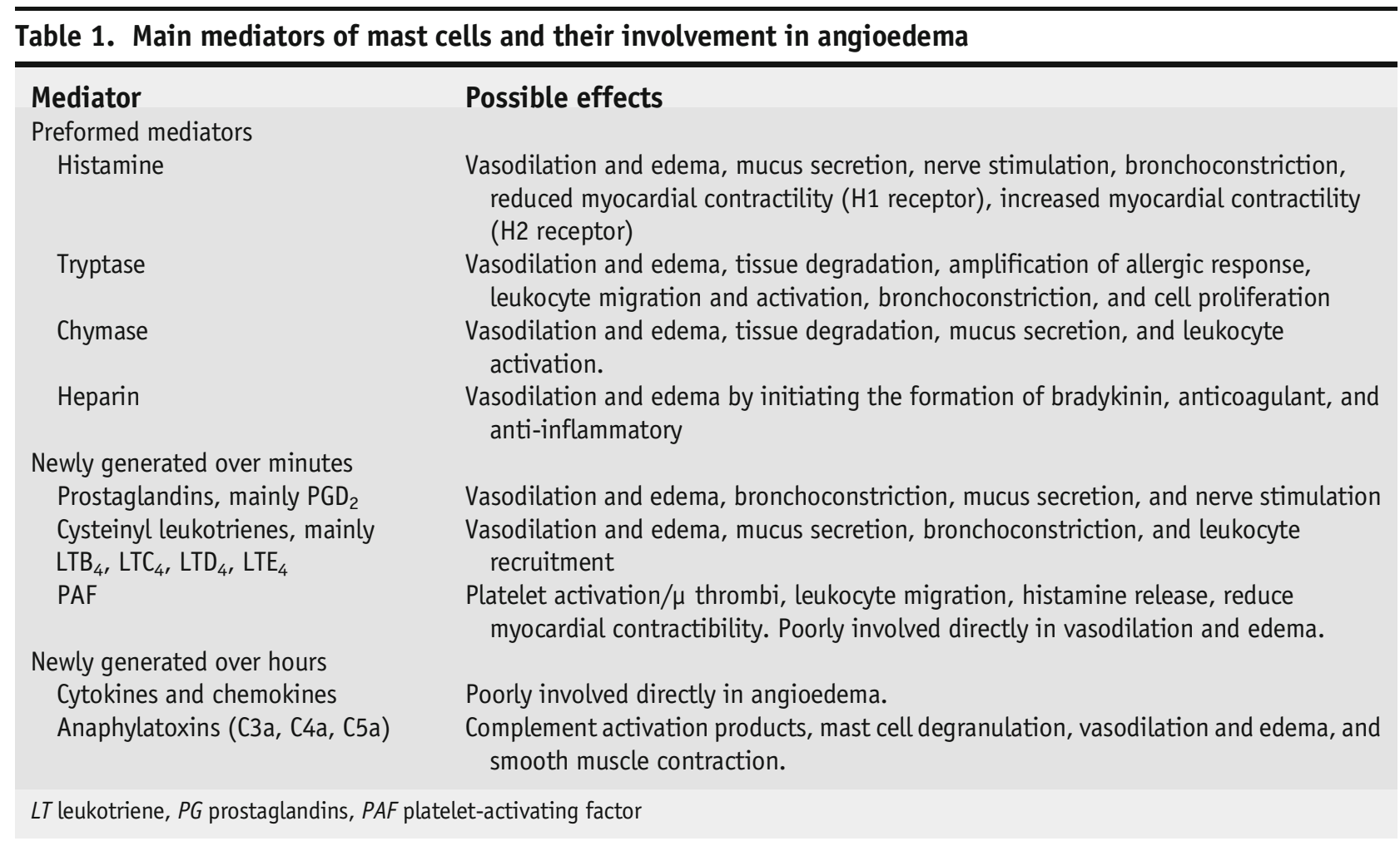

Nowadays, it is the best routine biomarker available to assess $\mathrm{MC}$ activation. MC tryptase belongs to the family of MC serine proteases and is present in large amounts in secretory granules of human MCs [26]. Tryptase is highly specific of $\mathrm{MC}$, so its detection provides information about MC distribution, number, activation status, or releasability. Tryptase is also produced in basophils but in much lower amounts [27, 28]. Sequential peak and baseline serum tryptase measurements help to detect mast cell activation. Levels are increased from $15 \mathrm{~min}$ to $3 \mathrm{~h}$ after anaphylaxis onset [29] or even longer [30], with the peak between 1 and $2 \mathrm{~h}$ [30]. However, its involvement in angioedema has not been established.

Histamine is the other biomarker available to assess MC activation; however, plasma histamine is quickly metabolized by $\mathrm{N}$ -

methyltransferase and diamine oxidase, its peaks within 5-10 min of the onset of symptoms and declines to baseline within $30 \mathrm{~min} \mathrm{[29].}$

Therefore, blood samples need to be obtained at the onset of symptoms, limiting its routine applicability. Histamine correlates with anaphylaxis severity [31], but again, data regarding its involvement in AE-WoW or its usefulness for the diagnosis are lacking. 


\section{Heparin}

This mediator may be involved in both types of angioedema, given that

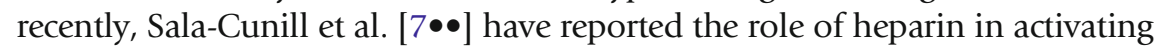
plasma contact system. They describe that IgE/antigen-stimulated MCs release heparin locally, which induces BK formation in a FXII-dependent manner in mice and also in human mast cell activation anaphylaxis. During anaphylaxis, patients presented a high-molecular-weight kyninogen cleavage with BK formation and high levels of anti-Xa (an indirect measure of plasma heparin) compared with controls. The study also suggests that activated MCs release heparin into circulation. This heparin, due to its negative charge, is a potent FXII contact activator in humans, inducing contact system-mediated BK formation in plasma. This BK will increase the vascular permeability. They also found a

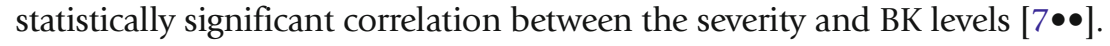
However, a routine validated method to measure BK directly does not exist. Therefore, its usefulness in the diagnosis of angioedema is unknown.

\section{Cysteinyl leukotrienes and prostaglandins}

Leukotriene C4 (LTC4) is the major 5-lipoxygenase product produced by activated MCs and basophils, although platelets, eosinophils, endothelial cells, and vascular smooth muscle cells also produce LTC4. It is rapidly metabolized to LTD4 and then to LTE4, which can be measured in urine [32].

Prostaglandin D2 (PGD2) is the main cyclooxygenase product produced by activated MCs but not by activated basophils. Like histamine and LTC4, clearance from the systemic circulation is rapid, and elevated serum levels are difficult to detect. Its metabolite (11-beta-PGF2-alfa) can be measured in urine and is more sensitive than N-methylhistamine [33]. However, measurement of PGD2 cannot be used in patients receiving cyclooxygenase inhibitors.

Both mediators can produce vasodilation and edema. However, nowadays, there is no routine laboratory method to measure them. In addition, both could be secreted by cells different from mast cell. Their usefulness in the diagnosis of angioedema has not yet been demonstrated.

Most of these mediators propagate and/or regulate the immune response and seem poorly involved in direct vasodilation and edema.

\section{Specific treatment options of angioedema without wheals: from old to novel therapies}

According to the potential mechanisms involved in each AE type, different therapeutic approaches may be considered. 


\section{Mast cell/basophil-related angioedema}

This group includes allergic AE, NSAIDS-AE, other drug-induced AE, and idiopathic $\mathrm{AE}$ responsive to antihistamines.

\section{Antihistamines}

The first line of treatment of acute angioedema in the emergency department is antihistamines and glucocorticoids. Also, removal of the offending agent is crucial in allergic or drug-induced angioedema [34].

First-generation $\mathrm{H} 1$ antagonists are the only antihistamines available for intravenous infusion (dexchlorpheniramine, diphenhydramine) [35]. Second-generation H1 antagonists may also be given because they are safe and well tolerated with very few and mild side effects, although this would be limited to the oral route $[36,37]$.

\section{Glucocorticosteroids}

There are no high-quality investigations assessing the use of glucocorticosteroids (GCS) in angioedema [38]. In fact, the optimal dose and duration of GCS treatment used for acute urticaria and angioedema have not been systematically studied, and the recommendations vary widely depending on the specialists and the countries [36]. However, when angioedema affects the respiratory airway, the use of steroids is beneficial in adults and in children [39]. In addition, GCS used in a short course for the acute attack are well tolerated and have few side effects.

\section{Adrenaline}

After a quick assessment, if a patient suffers an acute laryngeal edema, intramuscular adrenaline in the mid-anterolateral thigh may be lifesaving $[35,40]$. However, transient pharmacologic side effects after a recommended dose may occur. These are pallor, tremor, anxiety, dizziness, headache, and tachycardia. Other serious adverse effects (such as ventricular arrhythmias) normally occur after an overdose.

This group includes AAE-ACEi, AAE-C1INH, and HAE-C1INH (I and II), and probably HAE-nC1INH (HAE-FXII and HAE-unknown) and idiopathic unknown-AE. This type of angioedema does not respond to antihistamines, corticosteroids, or adrenaline $[2 \bullet \bullet]$. Recently, novel 
treatments have appeared for these types of angioedema, although we must keep in mind that much of the reported experience cited is from studies in HAE type I and II and further studies are needed to evaluate their efficacy in the others types of AE.

\section{Plasma-derived human C1 esterase inhibitor concentrate}

- Berinert $^{\circledast}$ (CSL Behring, Marburg, Germany): 20 U/kg body weight i.v. [41]

- Cinryze $^{\circledast}$ (Shire Orphan Therapies, Berlin, Germany): 1000 UI i.v. [42] Doses can be repeated as needed, usually after $1 \mathrm{~h}$. Tolerance is good for both manufactured concentrates. The main concern is the possible risk of transmission of infections given that they are plasma derived, although both are nanofiltrated and no viral transmission has been reported to date. This C1-INH replacement therapy restores the lacking C1-INH $[2 \bullet \bullet, 43]$. Phase II studies are ongoing for subcutaneous $\mathrm{C} 1$-inhibitor concentrate [44]. Furthermore, the recent changes of product licences allowing self-administration provide additional options for the management of HAE and improve the quality of life of these patients [45].

\section{Recombinant human C1 esterase inhibitor concentrate}

- Ruconest $^{\circledR}$ (Pharming Group NV, Leiden, The Netherlands): 50 U/kg body weight up to $4200 \mathrm{U}$ i.v. As the recombinant drug is produced by recombinant DNA technology in the milk of transgenic rabbits, it could induce allergic reactions in patients sensitized to rabbit dander. Thus, specific anti-rabbit IgE determination is recommended before using this product $[2 \bullet \bullet, 46]$.

\section{Bradykinin receptor antagonist}

- Icatibant acetate (Firazyr ; Shire Orphan Therapies, Berlin, Germany). European Public Assessment Report (EMEA 925383/ 2011) for Firazyr. 2011. Available at http://www.ema.europa.eu/ ema. Icatibant is a synthetic, decapeptide, short acting, and highly selective competitive BK B2 receptor antagonist, which inhibits the vasodilatation produced by BK. It is administered subcutaneously (30-mg/3-ml syringes). Its effectiveness has been 
shown in multiple clinical trials for patients with types I and II HAE [47, 48] and in case series in AAE-ACEi [49]. No serious adverse reactions have been reported.

\section{Plasma Kallikrein inhibitor}

- Ecallantide: (Kalbitor ; Dyax Corp., Cambridge, Mass, US). Ecallantide is a recombinant, 60 -aminoacid protein synthesized in the yeast Pichia pastoris which acts as a specific, reversible inhibitor of plasma kallikrein, the serum protease that produces BK. It is administered subcutaneously (30 mg in three vials of $10 \mathrm{mg} / \mathrm{ml}$ ) [50]. This inhibition helps to restore the balance between the production and degradation of BK. It is only approved by the FDA and not available in Europe [2]. Potentially serious hypersensitivity reactions, including anaphylaxis, occurred in $2.7 \%$ of patients.

\section{Antifibrinolytic agents}

- Tranexamic acid: (Amchafibrin ${ }^{\oplus}:$ Rottapharm, Barcelona, Spain). These drugs can be effective in an angioedema attack, but they are only recommended when the previously described treatments are not available. There are no data based on controlled clinical trials. High intravenous ( $15 \mathrm{mg} / \mathrm{kg} / 4 \mathrm{~h}$ iv) or oral doses of tranexamic acid have been used [2], and it has proven effective in prodromal phases of the attacks [51].

The efficacy of tranexamic acid in the prevention of angioedema attacks of HAE-C1INH has been shown in early clinical trials [52], and case series have also shown its effectiveness in the prophylactic treatment in idiopathic angioedema that does not respond to antihistamines [53, $54 \bullet$ 55].

\section{Conclusions}

In the last few years, progress about knowledge and treatment of angioedema has greatly improved. However, given that the different types of angioedema and the mechanisms involved are not fully understood, there are still many knowledge gaps that need to be overcome in order to improve the diagnosis, to be able to differentiate 
the different types of angioedema and to improve the accuracy in managing each patient.

\section{Compliance with Ethical Standards}

\section{Conflict of Interest}

Anna Sala-Cunill declares having received sponsorship for educational purposes, has been paid for consultancy services, and has taken part in clinical trials sponsored by Shire, CSL-Behring, Pharming NV, and Viropharma. Mar Guilarte declares having received sponsorship for educational purposes, has been paid for consultancy services, and has taken part in clinical trials sponsored by Shire, CSL-Behring, Pharming NV, and Viropharma.

\section{Human and Animal Rights and Informed Consent}

This article does not contain any studies with human or animal subjects performed by the authors.

\section{References and Recommended Reading}

Papers of particular interest, published recently, have been highlighted as:

- Of importance

$\bullet \quad$ Of major importance

1. Kaplan AP, Greaves MW. Angioedema. J Am Acad Dermatol. 2005;53:373-92.

2.• Cicardi M, Aberer W, Banerji A, Bas M, Bernstein JA, Bork $\mathrm{K}$, et al. Classification, diagnosis, and approach to treatment for angioedema: consensus report from the Hereditary Angioedema International Working Group. Allergy. 2014;69:602-16.

A review highlighting a novel classification, diagnosis and approach to treatment of angioedema as a consensus work from the hereditary Angioedema International working group.

3. Eli M, Joseph M, Kuznik B, Menachem S. Chronic idiopathic angioedema: a single center experience. Int J Dermatol. 2014;53:e421-7.

4. $\quad$ Powell RJ, Leech SC, Till S, Huber PAJ, Nasser SM, Clark AT. BSACI guideline for the management of chronic urticaria and angioedema. Clin Exp Allergy. 2015;45:547-65.

This guideline highlight the most important steps for the management of chronic urticaria and angioedema.

5. Nussberger J, Cugno M, Cicardi M, Agostoni A. Local bradykinin generation in hereditary angioedema. J Allergy Clin Immunol. 1999;104:1321-2.

6. Nussberger J, Cugno M, Amstutz C, Cicardi M, Pellacani A, Agostoni A. Plasma bradykinin in angiooedema. Lancet. 1998;351:1693-7.

7.• Sala-Cunill A, Björkqvist J, Senter R, Guilarte M, Cardona $\mathrm{V}$, Labrador $\mathrm{M}$, et al. Plasma contact system activation drives anaphylaxis in severe mast cell-mediated allergic reactions. J Allergy Clin Immunol 2014.
This study demonstrated the implication of the contact system in the physiopathology of mast cell activation anaphylaxis in human and in animals.

8. Oschatz C, Maas C, Lecher B, Jansen T, Bjorkqvist J, Tradler T, et al. Mast cells increase vascular permeability by heparin-initiated bradykinin formation in vivo. Immunity. 2011;34:258-68.

9. Giavina-Bianchi P, Aun MV, Motta AA, Kalil J, Castells $\mathrm{M}$. Classification of angioedema by endotypes. Clin Exp Allergy. 2015;45:1142-3.

10. Zuraw BL, Bork K, Binkley KE, Banerji A, Christiansen SC, Castaldo A, et al. Hereditary angioedema with normal $\mathrm{C} 1$ inhibitor function: consensus of an international expert panel. In Allergy and asthma proceedings : Off J Reg State Allergy Soc. 2012;33 Suppl 1.

11. Nosbaum A, Augey F, Nicolas J-F, Bérard F. [Pathophysiology of urticaria]. Ann Dermatol Venereol. 2014;141(Suppl):S559-64.

12. Hide M, Francis DM, Grattan CE, Hakimi J, Kochan JP, Greaves MW. Autoantibodies against the high-affinity IgE receptor as a cause of histamine release in chronic urticaria. N Engl J Med. 1993;328(22):1599-604.

13. Quiralte J, Avila-Castellano R, Cimbollek S. A phenotype-based classification of NSAIDs hypersensitivity: new patients, new challenges. Allergy. 2014;69:814-5.

14. Cugno M, Zanichelli A, Foieni F, Caccia S, Cicardi M C1-inhibitor deficiency and angioedema: molecular 
mechanisms and clinical progress. Trends Mol Med. 2009:69-78.

15. Kaplan AP, Ghebrehiwet B. The plasma bradykininforming pathways and its interrelationships with complement. Mol Immunol. 2010:2161-2169.

16. Hoover T, Lippmann M, Grouzmann E, Marceau F, Herscu P. Angiotensin converting enzyme inhibitor induced angio-oedema: a review of the pathophysiology and risk factors. Clin Exp Allergy. 2010:50-61.

17. Molinaro G, Cugno M, Perez M, Lepage Y, Gervais N, Agostoni A, et al. Angiotensin-converting enzyme inhibitor-associated angioedema is characterized by a slower degradation of des-arginine(9)-bradykinin. J Pharmacol Exp Ther. 2002;303:232-7.

18. Nussberger J, Cugno M, Cicardi M. Bradykininmediated angioedema. N Engl J Med. 2002;347:621-2.

19. Binkley KE. Factor XII mutations, estrogen-dependent inherited angioedema, and related conditions. Allergy Asthma Clin Immunol. 2010;6:16.

20. Hoem NO, Johannesen S, Hauge G, Rud AC, Sandem $S$, Briseid K. Contact activation factors in plasma from women using oral contraceptives - Increased levels of factor XII, kinin-free high molecular weight kininogen and acetone-activated kallikrein. Thromb Res. 1991;64:427-34.

21. Madeddu P, Emanueli C, Song Q, Varoni MV, Demontis MP, Anania V, et al. Regulation of bradykinin B2-receptor expression by oestrogen. $\mathrm{Br} \mathrm{J}$ Pharmacol. 1997;121:1763-9.

22. Drouet C, Désormeaux A, Robillard J, Ponard D, Bouillet L, Martin L, et al. Metallopeptidase activities in hereditary angioedema: effect of androgen prophylaxis on plasma aminopeptidase P. J Allergy Clin Immunol. 2008;121:429-33.

23. Kaplan AP, Joseph K. Pathogenic mechanisms of bradykinin mediated diseases: dysregulation of an innate inflammatory pathway. Adv Immunol. 2014;121:4189.

24. Joseph K, Tholanikunnel BG, Bygum A, Ghebrehiwet B, Kaplan AP. Factor XII-independent activation of the bradykinin-forming cascade: implications for the pathogenesis of hereditary angioedema types I and II. J Allergy Clin Immunol. 2013;132(2):470-5.

25. Williams CM, Galli SJ. The diverse potential effector and immunoregulatory roles of mast cells in allergic disease. J Allergy Clin Immunol. 2000;105:847-59.

26. McNeil HP, Adachi R, Stevens RL. Mast cellrestricted tryptases: structure and function in inflammation and pathogen defense. J Biol Chem. 2007:20785-20789.

27. Castells MC, Irani AM, Schwartz LB. Evaluation of human peripheral blood leukocytes for mast cell tryptase. J Immunol. 1987;138:2184-9.

28. Schwartz LB, Irani AM, Roller K, Castells MC, Schechter NM. Quantitation of histamine, tryptase, and chymase in dispersed human T and TC mast cells. J Immunol. 1987;138:2611-5.

29. Hogan AD, Schwartz LB. Markers of mast cell degranulation. Methods. 1997;13:43-52.
30. Sala-Cunill A, Cardona V, Labrador-Horrillo M, Luengo $\mathrm{O}$, Esteso $\mathrm{O}$, Garriga $\mathrm{T}$, et al. Usefulness and limitations of sequential serum tryptase for the diagnosis of anaphylaxis in 102 patients. Int Arch Allergy Immunol. 2013;160:192-9.

31. Stone SF, Cotterell C, Isbister GK, Holdgate A, Brown SG. Elevated serum cytokines during human anaphylaxis: identification of potential mediators of acute allergic reactions. J Allergy Clin Immunol. 2009;124:786-92 e4.

32. Ono E, Taniguchi M, Mita H, Fukutomi $\mathrm{Y}$, Higashi N, Miyazaki E, et al. Increased production of cysteinyl leukotrienes and prostaglandin D2 during human anaphylaxis. Clin Exp Allergy. 2009;39:72-80.

33. Awad JA, Morrow JD, Roberts LJ. Detection of the major urinary metabolite of prostaglandin D2 in the circulation: demonstration of elevated levels in patients with disorders of systemic mast cell activation. J Allergy Clin Immunol. 1994;93:81724.

34. Simons FER, Ardusso LRF, Bilò MB, El-Gamal YM, Ledford DK, Ring J, et al. World allergy organization guidelines for the assessment and management of anaphylaxis. World Allergy Organ J. 2011:13-36.

35. Frigas E, Park MA. Acute urticaria and angioedema: diagnostic and treatment considerations. Am J Clin Dermatol. 2009:239-250.

36. Sánchez-Borges M, Asero R, Ansotegui IJ, Baiardini I, Bernstein JA, Canonica GW, et al. Diagnosis and treatment of urticaria and angioedema: a worldwide perspective. World Allergy Organ J. 2012;5:125-47.

37. Zuberbier T, Asero R, Bindslev-Jensen C, Walter Canonica G, Church MK, Giménez-Arnau A, et al. EAACI/GA2LEN/EDF/WAO guideline: definition, classification and diagnosis of urticaria. Allergy Eur J Allergy Clin Immunol. 2009;64:1417-26.

38. Choo KJL, Simons E, Sheikh A. Glucocorticoids for the treatment of anaphylaxis: Cochrane systematic review. Allergy: Eur J Allergy Clin Immunol. 2010:1205-1211.

39. Rowe BH, Spooner C, Ducharme FM, Bretzlaff JA, Bota GW. Early emergency department treatment of acute asthma with systemic corticosteroids. Cochrane Database Syst Rev. 2001:CD002178.

40. Bernstein JA, Moellman J. Emerging concepts in the diagnosis and treatment of patients with undifferentiated angioedema. Int J Emerg Med. 2012;5:39.

41. Busse P, Bygum A, Edelman J, Lumry W, Machnig T, Martinez-Saguer I, et al. Safety of C1-esterase inhibitor in acute and prophylactic therapy of hereditary angioedema: findings from the ongoing international Berinert patient registry. J Allergy Clin Immunol Pract 3:213-9.

42. Zuraw BL, Busse PJ, White M, Jacobs J, Lumry W, Baker J, et al. Nanofiltered C1 inhibitor concentrate for 
treatment of hereditary angioedema. N Engl J Med. 2010;363:513-22.

43. Craig TJ, Schneider LC, MacGinnitie AJ. Plasma-derived C1-INH for managing hereditary angioedema in pediatric patients: a systematic review. Pediatr Allergy Immunol. 2015.

44. Zuraw BL, Cicardi M, Longhurst HJ, Bernstein JA Li HH, Magerl M, et al. Phase II study results of a replacement therapy for hereditary angioedema with subcutaneous $\mathrm{C} 1$-inhibitor concentrate. Allergy. 2015.

45. Caballero T, Sala-Cunill A, Cancian M, Craig TJ, Neri S, Keith PK, et al. Current status of implementation of self-administration training in various regions of Europe, Canada and the USA in the management of hereditary angioedema. Int Arch Allergy Immunol. 2013;161(Suppl):10-6.

46. Moldovan D, Bernstein JA, Cicardi M. Recombinant replacement therapy for hereditary angioedema due to $\mathrm{C} 1$ inhibitor deficiency. Immunotherapy. 2015:1-14.

47. Cicardi M, Banerji A, Bracho F, Malbrán A, Rosenkranz B, Riedl M, et al. Icatibant, a new bradykinin-receptor antagonist, in hereditary angioedema. N Engl J Med. 2010;363:532-41.

48. Maurer M, Aberer W, Bouillet L, Caballero T, Fabien V, Kanny G, et al. Hereditary angioedema attacks resolve faster and are shorter after early icatibant treatment. PLoS One. 20138.

49. Bova M, Guilarte M, Sala-Cunill A, Borrelli P, Rizzelli GML, Zanichelli A. Treatment of ACEI-related angioedema with icatibant: a case series. Intern Emerg Med. 2015;10:345-50.

50. Cicardi M, Levy RJ, McNeil DL, Li HH, Sheffer AL, Campion M, et al. Ecallantide for the treatment of acute attacks in hereditary angioedema. N Engl J Med. 2010;363:523-31.

51. Sheffer AL, Fearon DT, Austen KF, Rosen FS. Tranexamic acid: preoperative prophylactic therapy for patients with hereditary angioneurotic edema. J Allergy Clin Immunol. 1977;60:38-40.

52. Sheffer AL, Austen KF, Rosen FS. Tranexamic acid therapy in hereditary angioneurotic edema. N Engl J Med. 1972;287:452-4.

53. Cicardi M, Bergamaschini L, Zingale LC, Gioffré D, Agostoni A. Idiopathic nonhistaminergic angioedema. Am J Med. 1999;106:650-4.

54. Mansi M, Zanichelli A, Coerezza A, Suffritti C, Wu MA, Vacchini R, et al. Presentation, diagnosis and treatment of angioedema without wheals: a retrospective analysis of a cohort of 1058 patients. J Intern Med. 2015;277:585-93.

A study highlighting the usefulness of the hereditary Angioedema International working group classification and also the different profile of presentation, diagnosis and treatment of each type of angioedema without wheals.

55. Wintenberger C, Boccon-Gibod I, Launay D, Fain O, Kanny G, Jeandel PY, et al. Tranexamic acid as maintenance treatment for non-histaminergic angioedema: analysis of efficacy and safety in 37 patients. Clin Exp Immunol. 2014;178:112-7. 